\title{
Bilateral posterior circulation stroke secondary to a crotalid envenomation: case report
}

\author{
Thiago Cardoso Vale ${ }^{[1]}$, Alysson Ferreira Leite ${ }^{[2]}$, Priscila Ribeiro da Hora ${ }^{[2],}$ \\ Marayra Inês França Coury ${ }^{[2]}$, Ricardo Cipriano da Silva ${ }^{[2]}$ \\ and Antônio Lúcio Teixeira ${ }^{[3]}$
}

[1]. Serviço de Neurologia, Hospital das Clínicas, Universidade Federal de Minas Gerais, Belo Horizonte, MG. [2]. Departamento de Clínica Médica, Hospital Júlia Kubitschek, Belo Horizonte, MG. [3]. Departamento de Clínica Médica, Faculdade de Medicina, Universidade Federal de Minas Gerais, Belo Horizonte, MG.

\begin{abstract}
Snake bite envenoming is a disease with potential serious neurological complications. We report a case of an adolescent who was bitten by a rattlesnake and developed bilateral posterior circulation stroke. The rattlesnake was later identified as being Crotalus durissus terrificus. Stroke was probably due to toxic vasculitis or toxin-induced vascular spasm and endothelial damage.
\end{abstract}

Keywords: Stroke. Snake bite. Venom. Crotalus durissus terrificus.

\section{INTRODUCTION}

Snake bite envenoming is a neglected disease affecting millions of people living in the developing world ${ }^{1}$. Serious neurological complications, including stroke and muscle paralysis, are related to the toxic effects of the venom ${ }^{2}$. In a study of 309 patients bitten by Bothrops spp., Mosquera et al. ${ }^{3}$ reported cerebrovascular complications in $8(2.6 \%)$ patients, being 7 hemorrhagic strokes and 1 ischemic stroke. Afibrinogenemia has been linked to rattlesnake bites and might explain the higher incidence of hemorrhagic strokes ${ }^{4,5}$. This paper aims to report a patient who developed stroke secondary to a rattlesnake bite. Medical chart review was performed in a tertiary-care hospital in Belo Horizonte, Minas Gerais, Brazil.

\section{CASE REPORT}

A 16-year-old previously healthy Brazilian adolescent was victimized by a snake bite on his left foot while farming. Shortly after, he complained of mild localized erythema and pain, and was admitted to a community outpatient unit. He received antibothropic serum six hours after the bite which was initially attributed to a Viperidae snake, more commonly seen in the region. He was discharged without any laboratory tests or observational period. On the following day, he was admitted to hospital due to somnolence, bilateral palpebral weakness and darkened urine as a result of myoglobinuria

Address to: Dr. Thiago Cardoso Vale. Serviço de Neurologia/HC/UFMG. Av. Professor Alfredo Balena 110, Bairro Santa Efigênia, 30130-100 Belo Horizonte, MG, Brasil.

Phone: 5531 3409-9417

e-mail: thiagocardosovale@hotmail.com

Received 12 June 2012

Accepted 16 July 2012 with creatine phosphokinase levels at 390,000U/dL. Creatinine and potassium levels were high $(2.3 \mathrm{mg} / \mathrm{dL}$ and $6.0 \mathrm{mg} / \mathrm{dL}$, respectively) and progressively increased despite hydration and urine alcalinization. He was then submitted to hemodyalisis and oro-intubation after having received $200 \mathrm{ml}$ (20 ampoules) of an intravenous crotalid antivenom after further description of the snake by the patient's relatives. After a week of intensive care and initial clinical and laboratory improvement, he developed diplopia, bilateral visual impairment and headache. Blood coagulation screens and ecocardiography were normal. Cranial computed tomography scan showed bilateral occipital ischemia with diffuse edema and intracranial hypertension. Brain magnetic resonance imaging confirmed a predominantly left temporo-occipital infarct with areas of ischemia in the pons and cerebellum, without any abnormalities in the magnetic resonance angiography (Figure $\mathbf{1}$ and 2). He was diagnosed as having a stroke (top-of-the-basilar syndrome) secondary to a rattlesnake bite later identified as being Crotalus durissus terrificus, identified by a physician expert on toxicology (Dr. A.F.L). The patient remained with a severe behavioral and cognitive impairment, with mini-mental state examination of $12 / 30$ and proeminent apathy. He also had gait difficulty due to spastic tetraparesis and tetrahyperreflexia, and an important visual compromise.

\section{DISCUSSION}

Ischemic stroke following a rattlesnake bite is very rarely reported in the literature. In a Brazilian study with 249 cases of rattlesnake bites, 99 out of 100 snakes classified as subspecies were Crotalus durissus terrificus. Most of the patients were male $(80.7 \%)$, the superior limbs were bitten in $66.4 \%$ of the cases and the most frequent clinical manifestations were pain (61\%), local edema (55\%), palpebral ptosis (75.9\%), myoglobinuria (38.6\%) and myalgia (36.1\%). Only one patient presented with ischemic stroke ${ }^{6}$. 


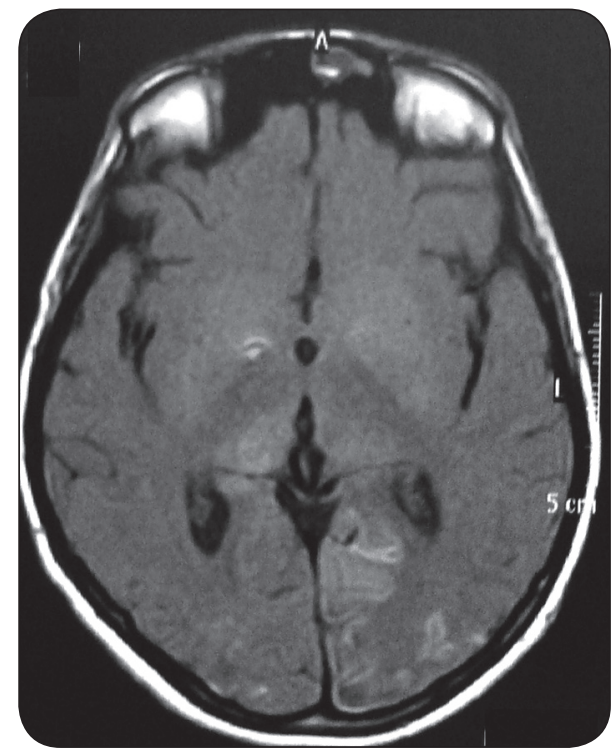

FIGURE 1 - Axial T1-weighted-sequenced, contrast enhanced, brain magnetic resonance imaging showing bilateral hyperintense lesions in the occipital lobes, with evident left predominance, and bilaterally in pulvinar nuclei of the thalamus.

There are several putative mechanisms by which cerebral infarction may occur in envenomation by snakes in general: a) hypotension due to hypovolemia from multiple causes, including sweating, vomiting, decreased fluid intake, increased vascular permeability due to systemic inflammatory response and bleeding, which leads to low flow state and watershed infarction; b) hypercoagulability due to procoagulants in the venoms or consumption coagulopathy phase of disseminated intravascular coagulopathy; c) adverse venom serum reaction, leading to vasculitis and thrombosis; d) endothelial injury due to toxic vasculitis ${ }^{7}$. Central nervous system edema and hemorrhage was reported in a few cases of crotalid envenomation ${ }^{2,4,5,8}$, but the most common cause was progressive shock leading to multiorgan failture and death hours to a few days later. Edema is a result of the direct effect of the toxin on the integrity of the circulation and the microcirculation in particular ${ }^{8}$.

Our patient was young and without any vascular risk factors. He developed stroke symptoms delay of one week after the bite, but not explained by any hospital-associated complication. Magnetic resonance angiography and blood coagulation routine screen were normal. Together, these facts suggest that the cerebral infarction was the result of toxic vasculitis or toxininduced vascular spasm and endothelial damage ${ }^{1,2,9,10}$. A $24 \mathrm{~h}$ delay in treatment might have contributed to worsen prognosis in our patient. Following snake bite, emphasis should be given

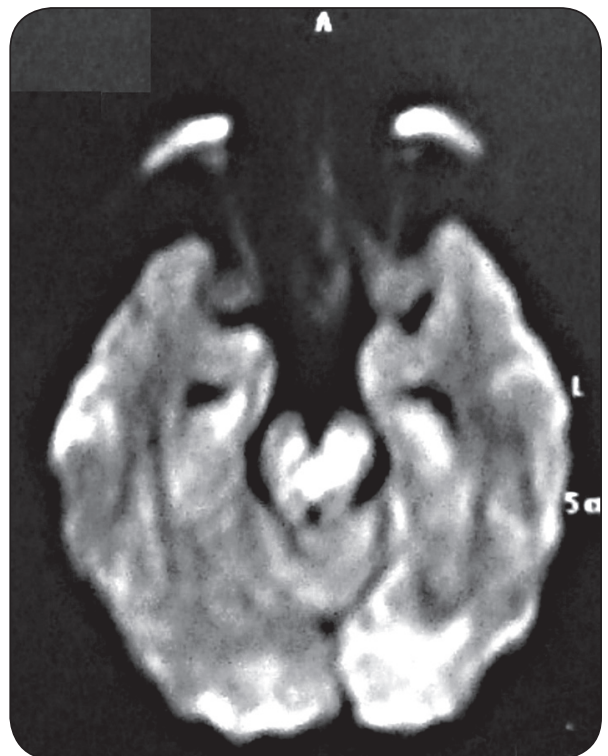

FIGURE 2 - Axial diffusion-weighted brain magnetic resonance imaging showing a bilateral occipital infarct and a central pontine hyperintense lesion.

in the prompt treatment because the most important factor in determining survival following a severe envenomation is the amount of time elapsed between the bite and specific treatment.

\section{REFERENCES}

1. Warrell DA. Snake bite. Lancet 2010; 375:77-88.

2. Del Brutto OH, Del Brutto VJ. Neurological complications of venomous snake bites: a review. Acta Neurol Scand 2012; 125:363-372.

3. Mosquera A, Idrovo LA, Tafur A, Del Brutto OH. Stroke following Bothrops spp. snakebite. Neurology 2003; 60:1577-1580.

4. Amaral CF, Rezende NA, Pedrosa TM, Silva OA, Pedroso ER. Afibrinogenemia secondary to crotalid snake bite (Crotalus durissus terrificus). Rev Inst Med Trop Sao Paulo 1988; 30:288-292.

5. Amaral CF, Silva OA, López M, Pedroso ER. Afibrinogenemia following snake bite (Crotalus durissus terrificus). Am J Trop Med Hyg 1980; 29:1453-1455.

6. Jorge MT, Ribeiro LA. The epidemiology and clinical picture of an accidental bite by the South American rattlesnake (Crotalus durissus). Rev Inst Med Trop Sao Paulo 1992; 34:347-354.

7. Panicker JN, Madhusudhanan S. Cerebral infarction in a young male following viper envenomation. J Assoc Physicians India 2000; 48:744-745.

8. Kitchens C, Eskin T. Fatality in a case of envenomation by Crotalus adamanteus initially successfully treated with polyvalent ovine antivenom followed by recurrence of defibrinogenation syndrome. J Med Toxicol 2008; 4:180-183.

9. Bashir R, Jinkins J. Cerebral infarction in a young female following snake bite. Stroke 1985 ; 16:328-330.

10. Lee BC, Hwang SH, Bae JC, Kwon SB. Brainstem infarction following Korean viper bite. Neurology 2001; 56:1244-1245. 